\title{
Study on Glass-Epoxy-Based Low-Cost and Compact Tip-Truncated Triangular Printed Antenna
}

\author{
Rajeev Kumar Kanth, ${ }^{1}$ Pasi Liljeberg,, ${ }^{1}$ Hannu Tenhunen, ${ }^{1}$ Qiang Chen, ${ }^{2}$ Lirong Zheng, \\ and Harish Kumar ${ }^{3}$ \\ ${ }^{1}$ Turku Centre for Computer Science (TUCS) and Department of Information Technology, University of Turku, 20520 Turku, Finland \\ ${ }^{2}$ School of Information and Communication Technologies, Royal Institute of Technology (KTH), 10044 Stockholm, Sweden \\ ${ }^{3}$ Department of Electronics and Communication Engineering, BIT, Muzaffarnagar 251315 (U.P.), India
}

Correspondence should be addressed to Rajeev Kumar Kanth, rajkan@utu.fi

Received 11 February 2012; Revised 1 June 2012; Accepted 1 June 2012

Academic Editor: Dalia N. Elshiekh

Copyright (C) 2012 Rajeev Kumar Kanth et al. This is an open access article distributed under the Creative Commons Attribution License, which permits unrestricted use, distribution, and reproduction in any medium, provided the original work is properly cited.

\begin{abstract}
Printed antennas based on glass epoxy substrate have been developed. On the basis of required specifications and assigned frequencies, tip-truncated triangular printed antennas have been designed, analyzed, and fabricated. The performances of the antennas have been measured in terms of return loss, frequency of operation, bandwidth, and radiation pattern. Triangular microstrip antenna (TMSA) configuration consisting of copper as active radiating patch and glass epoxy as dielectric substrate has been screened out to achieve the essential characteristics and satisfying recommended low-cost antenna. The Method of Moment (MOM) analyzing techniques have been employed to realize the required specific properties, whereas optimized tip truncation technique and varying feed point location give rise to suitable LHCP or RHCP configuration of the printed antenna. The coaxial probe signal feed arrangement have been considered for this work. The proposed printed antennas are suitable for communication links between ships or buoys and satellites specially for navigation purpose.
\end{abstract}

\section{Introduction}

The rapid progress in telecommunications has to deal with a great variety of communication systems, like cellular communications, global positioning, and satellite communications, each of these systems operate at several frequency bands. To provide an efficient and seamless services to the users, each of these systems must have an antenna that has to operate in the allocated frequency band for each specific system. Dielectric material plays an important role to characterize the performance of a microstrip antenna [1-4]. Usually, it is difficult to configure and optimize the parameters of an antenna with known value of dielectric constant. In this work, we have selected a widely available and low-cost dielectric material for design and fabrication of the antennas. Glass-epoxy dielectric material has several advantages such as rigid, low cost, uniform permittivity, and fine dielectric loss tangent characteristics over other substrates. A glass-epoxy substrate, which is generally used as printed circuit board for analog and digital circuits, can also be used for low-cost applications. The relative dielectric constant $\left(\varepsilon_{r}\right)$ of the substrate varies typically from 3.8 to 4.7 and tangent loss varies from 0.01 to 0.03 in the microwave frequency band.

Another major constraint resource is the frequency of operation. International Telecommunication Union Radio Communication Sector (ITU-R) has assigned two frequencies $1.176 \mathrm{GHz}$ and $2.487 \mathrm{GHz}$ for Regional Navigation Satellite System (RNSS) for the purpose of satellite navigational aids. The objective of this paper is to design and develop two separate antennas resonating at those specific frequencies accomplishing the required bandwidths, axial ratios, and gain radiation patterns.

A microstrip printed antenna consists of a very thin radiating patch on one side of a dielectric substrate and a conducting ground plane on the other side. The patch and the ground plane are separated by a dielectric. In this work, copper has been taken into consideration as a radiating patch 
conductor and it can have any regular geometry. The patches are usually photoetched on the dielectric substrate and the substrate is usually nonmagnetic. The relative permittivity of the substrate is an important parameter to consider because it will enhance the fringing fields that accounts for radiation. To achieve the design specification for these separate $1.176 \mathrm{GHz}$ and $2.487 \mathrm{GHz}$ antennas, substrate is considered as glass epoxy whose relative dielectric constant $\left(\varepsilon_{r}\right)$ is 4.4 and dimensions of the antenna is set up by the empirical relationship [5] as illustrated in (1), (2), (3), and (4) for Equilateral Triangle Micro Strip Antenna (ETMSA). MathCAD 2000 tool has been used to find the exact dimensions of both antennas.

This work is an extension of our previous studies on low profile microstrip antenna [6-11]. In recent years, several microstrip patch geometries have been introduced for antenna applications with varying degrees of success in improving antenna characteristics [12-18]. Some of these geometries have been particularly useful in reducing the size of the antenna. However, the proposed models are appropriate for the specified frequencies, respectively, in $L$ and $S$ band having the gain of $-4 \mathrm{dBi}$ up to $\pm 50^{\circ}$ and can be employed in the application of satellite navigation.

This paper is structured as follows. Sections 2 and 3 provide the description about related antenna theory and specifications of the antennas, respectively. Section 4 will present the design layout, physical dimensions, and probe positions of the proposed antennas. Section 5 is dedicated to exemplify the outcomes obtained and their analysis in each antenna configuration. This paper also includes the fabrication process and measurement techniques which are discussed in Sections 6 and 7, respectively. Conclusion, Acknowledgment, and References are the latter appendages of this paper.

\section{Related Theory}

Related antenna theory has been discussed in this section. The aim of this section is to clarify the readers about mathematical computation of specified parameters during antenna design. Figure 1 characterizes the dominant mode of ETMSA, $\mathrm{TM}_{10}$ and $\mathrm{TM}_{01}$ are required to configure circular polarization, and this figure also elucidates voltage distribution and field vector representation around ETMSA. The set of four equations help to determine the dimensions of both antennas

$$
\begin{gathered}
f_{m n}=\frac{2 c\left(m^{2}+m n+n^{2}\right)^{1 / 2}}{3 S_{e \sqrt{\varepsilon_{e}}}}, \\
S_{e}=S+\frac{4 h}{\varepsilon_{e}}, \\
\varepsilon_{e}=\frac{\left(\varepsilon_{r}+1\right)}{2}+\frac{\left(\varepsilon_{r}-1\right)}{2}\left[1+\frac{20 h}{S}\right]^{-1 / 2}, \\
y=\sqrt{S^{2}-\left(\frac{S}{2}\right)^{2}} .
\end{gathered}
$$

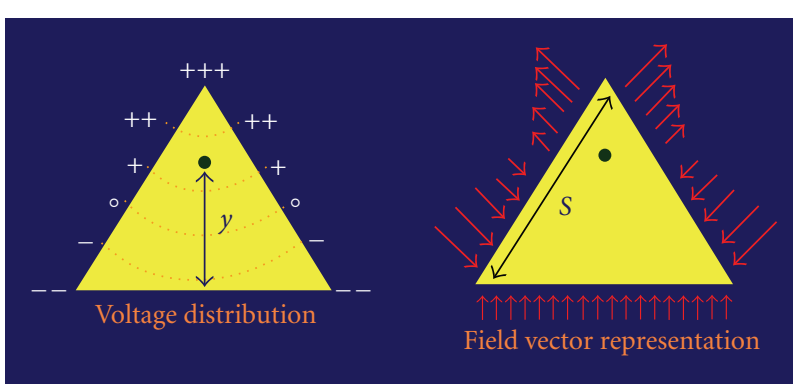

FIGURE 1: ETMSA voltage distribution and its vector representation.

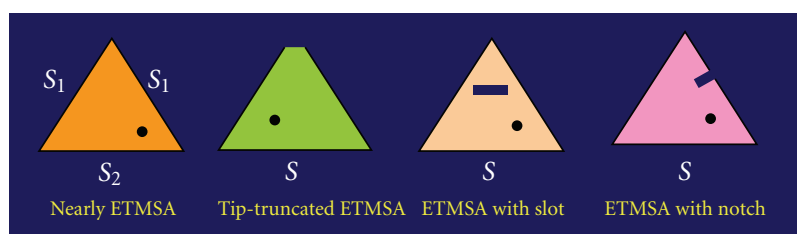

FIgURE 2: Methods obtaining circular polarization.

The resonant frequency $\left(f_{m n}\right)$ can be expressed in terms of effective side length $\left(S_{e}\right)$, mode of triangular patch antenna ( $m=1, n=0$ ), speed of light $(c)$, and the effective dielectric constant $\left(\varepsilon_{e}\right)$. Similarly, the effective side length can be estimated with (2) where effective dielectric constant $\left(\varepsilon_{e}\right)$ can be obtained in (3) with the use of associated parameters like relative dielectric constant $\left(\varepsilon_{r}\right)$, height, or thickness of the ground plane to patch $(h)$ and side of equilateral triangle $(S)$. The empirical mathematical statements shown in (1), (2), (3), and (4) assist to compute the dimensions of the active patches. MathCAD 2000 tool has been employed to achieve the optimized parameters.

Modified triangular MSA configuration with a single feed generates circular polarization. Some of the well-known techniques for generating circular polarization in ETMSA are nearly ETMSA (isosceles triangle with $S_{1} / S_{2}=1.01$ to 1.1), tip-truncated ETMSA, ETMSA with a rectangular slot and notched ETMSA as shown in Figure 2. LHCP or RHCP can be obtained by variation of feed point location and dimensions of the antenna. For the sake of convenience and easy realization, tip-truncated ETMSA has been employed for these designs. For these developed antennas, coaxial probe feeding technique has been exploited. The coaxial feed or probe feed is a very common technique used for feeding microstrip patch antennas. In this technique, inner conductor of the coaxial connector extends through the dielectric and is soldered to the radiating patch, while the outer conductor is connected to the ground plane. For the present design, the substrate chosen is glass epoxy and the reasons for selection of glass epoxy are low cost, compact size and easily available for mass production.

\section{Specifications}

A specification is an explicit set of requirements to be satisfied by the antenna. The technical specifications for 
TABLE 1: Specifications of $1.176 \mathrm{GHz}$ and $2.487 \mathrm{GHz}$ antennas.

\begin{tabular}{|c|c|c|c|c|}
\hline $\begin{array}{l}\text { Serial } \\
\text { number }\end{array}$ & Parameters & $\begin{array}{c}1.176 \mathrm{GHz} \\
\text { antenna }\end{array}$ & $\begin{array}{c}2.487 \mathrm{GHz} \\
\text { antenna }\end{array}$ & Unit \\
\hline (1) & $\begin{array}{l}\text { Frequency } \\
\text { band }\end{array}$ & $1.16-1.19$ & $2.46-2.50$ & $\mathrm{GHz}$ \\
\hline (2) & Gain & -4 (Minimum) & -4 (Minimum) & $\begin{array}{l}\mathrm{dBi} \text { up to } \\
\pm 50^{\circ}\end{array}$ \\
\hline (3) & Axial ratio & 3 & 3 & $\mathrm{~dB}$ \\
\hline (4) & Polarization & LHCP & LHCP & \\
\hline (5) & $\begin{array}{c}3 \mathrm{~dB} \text { beam } \\
\text { width }\end{array}$ & $\pm 50^{\circ}$ & $\pm 50^{\circ}$ & \\
\hline
\end{tabular}

both the antennas have been shown in Table 1. Based on communication link between associated application and the satellite, this technical specification came in to the picture. It is evident from Table 1 that antennas bandwidth must large enough such that frequency of operation has to be included within the band. The numerical values of the bandwidths are $30 \mathrm{MHz}$ and $40 \mathrm{MHz}$, respectively, for both the antennas respectively. Apart from bandwidth consideration, the gain must exceed $-4 \mathrm{dBi}$ and feed point must be set up such that left-hand circular polarization (LHCP) is obtained.

\section{Design Layout}

This section deals with the layout for both antennas. We will discuss design criteria regarding physical dimensions as well as probe position.

The layout of the $1.176 \mathrm{GHz}$ microstrip antenna is shown in Figure 3. In this layout, tip-truncated ETMSA has been devised to get the circular polarization. Truncated portion creates two dominant modes with equal amplitude and $90^{\circ}$ phase difference. Both modes are applied on orthogonal plane to generate circular polarization. This method is employed because of good axial ratio and bandwidth. The sides of the patch have been optimized as $72.43 \mathrm{~mm}$, $78.55 \mathrm{~mm}$, and $72.45 \mathrm{~mm}$, respectively, for three sides of the triangle. These lengths of the patch side offer the required specification of the antenna operating at $1.176 \mathrm{GHz}$. The probe position plays a significant role in designing the patch antenna. Several iterations have been performed to achieve the exact impedance matching. At the same time, the resonant frequency is controlled by changes in dimensions of the patch. For the design of $1.176 \mathrm{GHz}$ patch, it has been noticed that port $P$ of coordinate $(1.9,35.4)$ in Figure 3 is required position of the probe for maximum impedance matching where the lower vertex of the antenna is assumed at the position $(0,0)$.

The layout of the $2.487 \mathrm{GHZ}$ microstrip antenna is also similar to Figure 3. As shown in Figure 3, the sides of the patch have been optimized as $31.1 \mathrm{~mm}, 36.5 \mathrm{~mm}$, and $31.1 \mathrm{~mm}$, respectively, for three sides of the triangle. These lengths of the patch sides offer the required specification of the antenna operating at $2.487 \mathrm{GHz}$. For the design of $2.487 \mathrm{GHz}$ patch, we have noticed that port $P$ of coordinate
$(0.78,15)$ in Figure 3 is required position of the probe for maximum impedance matching where the lower vertex of the antenna is assumed at the position $(0,0)$.

\section{Outcomes of $1.176 \mathrm{GHz}$ and 2.487 GHz Antenna}

This section discusses simulated and measured results. We have attempted to analyze the specific design parameters in Section 3 for $1.176 \mathrm{GHz}$ antenna. An electromagnetic modeling tool, Ansoft designer, has been employed to simulate the required specifications of the antenna. The following subsection deals with the results in terms of return loss, bandwidth, smith plot, axial ratio, and gain radiation pattern.

\subsection{Outcomes of $1.176 \mathrm{GHz}$ Antenna}

5.1.1. Outcomes. Figure 4 is return loss diagram analyzed using Ansoft designer version 2 software tool. It points out that the antenna is resonating at $1.176 \mathrm{GHz}$ frequency and providing a large enough bandwidth of $30 \mathrm{MHz}$ ranging from $1.17 \mathrm{GHz}$ to $1.20 \mathrm{GHz}$ at the level of $10 \mathrm{~dB}$ return loss. This value of bandwidth has been achieved after several iterations optimizing several parameters in the design. The measured return loss curves have been also presented in Figure 4. The desired frequency of operation has been attained on $4.8 \mathrm{~mm}$ thickness of the substrate. As glassepoxy substrate sheet was available with $1.6 \mathrm{~mm}$ thickness, and the required thickness of the substrate was $4.8 \mathrm{~mm}$ (according to design), therefore, three layers of the substrate were stacked together to get the desired thickness for the specific design. These three layers have been stacked by two ways; firstly, they have been stacked with air gapping and secondly, they have been stacked using the adhesive. In both the cases measurements have been carried out. Simulated and measured impedance matching plots have been performed using Ansoft tool and Vector Network Analyzer (VNA), respectively. The reflection coefficient and impedance matching were found exactly as desired. Gain radiation pattern and axial ratio diagrams are shown in Figures 5 and 6, respectively.

5.1.2. Results Analysis. For $1.176 \mathrm{GHz}$ antenna, Figure 4 is showing that the antenna is resonating at $1.176 \mathrm{GHz}$ corresponding to lower data cursor in simulated labeled return loss curve. This depicts that at $10 \mathrm{~dB} S_{11}$, bandwidth of $30 \mathrm{MHz}$ is achieved ranging from $1.17 \mathrm{GHz}$ to $1.20 \mathrm{GHz}$. The measured return loss with adhesive and air gap have been shown with corresponding lower cursor points in the same Figure 4. In our design, the center frequency is $1.176 \mathrm{GHz}$ but the measured center frequency using Vector Network Analyzer (VNA) becomes $1.226 \mathrm{GHz}$ in case of air gap and $1.221 \mathrm{GHz}$ in case of adhesive, both of them are shifted toward the right. The possible reasons for center frequency shift and bandwidth are as follows. 


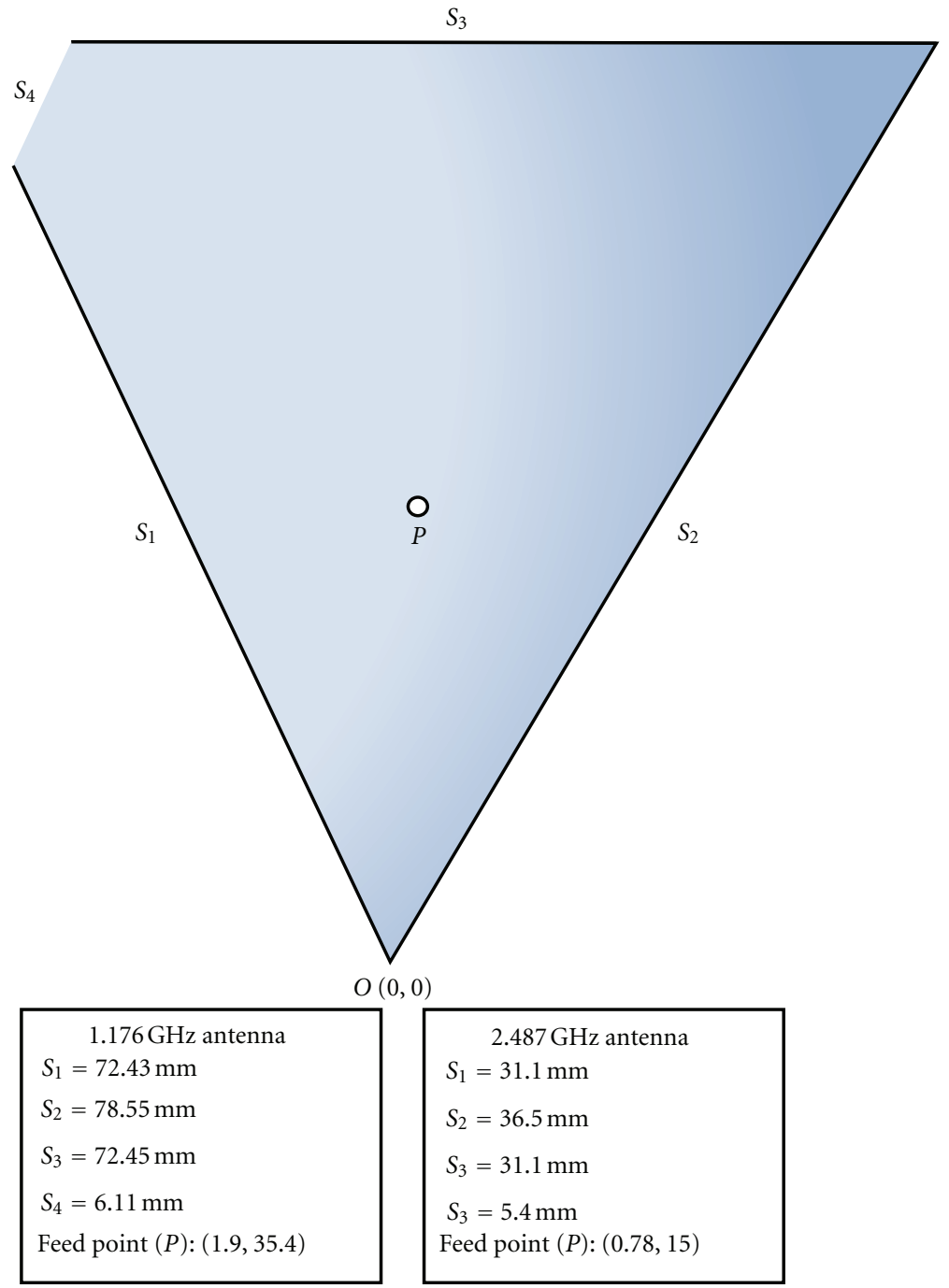

FIgURE 3: Layout of $1.176 \mathrm{GHz}$ and $2.487 \mathrm{GHz}$ Antennas.

(i) We have considered the dielectric material of thickness $4.8 \mathrm{~mm}$, but it is not available with this thickness. Therefore, three $1.6 \mathrm{~mm}$ sheets of glass epoxy are stacked together to get the desired specification.

(ii) Another reason for frequency shift is that the effective dielectric constant must decrease due to insertion of some gaps among these three layers of glass epoxy.

In a similar way, the return loss of the antenna is measured with the air gap in between the sheets of the glass epoxy, which is also shifted due to the change in the effective dielectric material of the antenna.

The simulated impedance plot shows that there is a loop formation near 1.0, which indicates that the antenna is circularly polarized, and inductive reactance is created by a change in thickness of actual hardware. The resonant frequency, that is, $1.176 \mathrm{GHz}$, is at the nearest point in the loop that shows the perfect behavior of the patch antenna. The measuring Smith plot for both adhesive and air gap
1.176 GHz antenna have been performed. The measured and simulated impedance plots are very close to each other.

From gain radiation pattern, shown in Figure 5, it can be stated that the gain along the bore sight is around $5.14 \mathrm{dBi}$. The radiation pattern has been constructed for three different angles of $\Phi$, that is, $0^{\circ}, 45^{\circ}$, and $90^{\circ}$, which gives the pattern appropriate to the specification. For the angle theta $(\theta)$ of $\pm 70^{\circ}$, the gain pattern is reasonable. The axial ratio for the specified patch antenna is shown in Figure 6. It has been shown that the axial ratio is $2.17 \mathrm{~dB}$ and in practical case it should be less than $3 \mathrm{~dB}$. Hence, this also fulfills the requirement of the design. Figure 7 is the actual $1.176 \mathrm{GHz}$ antenna developed fulfilling the required specification showing its patch side where as the other side of the antenna has a coaxial probe, soldered with the patch through $3 \mathrm{~mm}$ Via.

5.2. Outcomes of $2.487 \mathrm{GHz}$ Antenna. This section discusses simulated and measured results. We have attempted to analyze the appropriate designing parameters in Section 3 


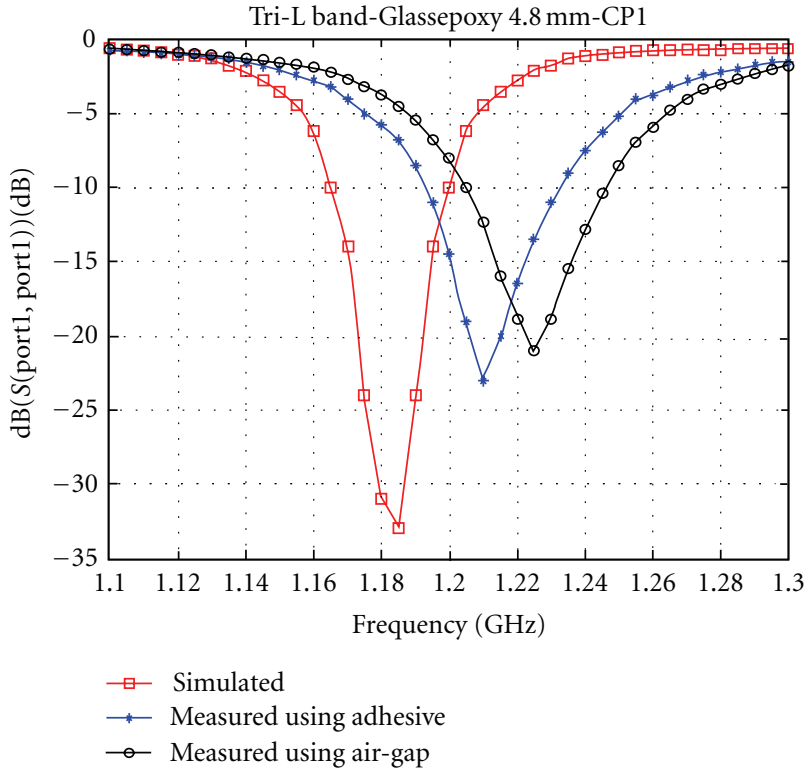

FIgURE 4: Return loss diagram.

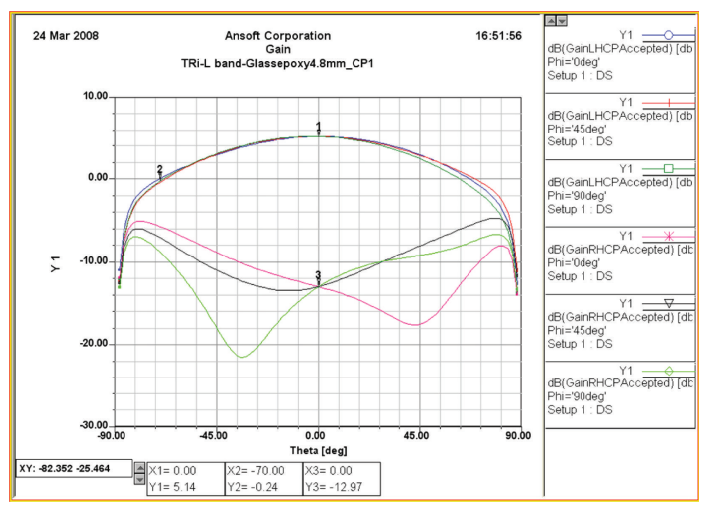

FIGURE 5: Gain radiation pattern.

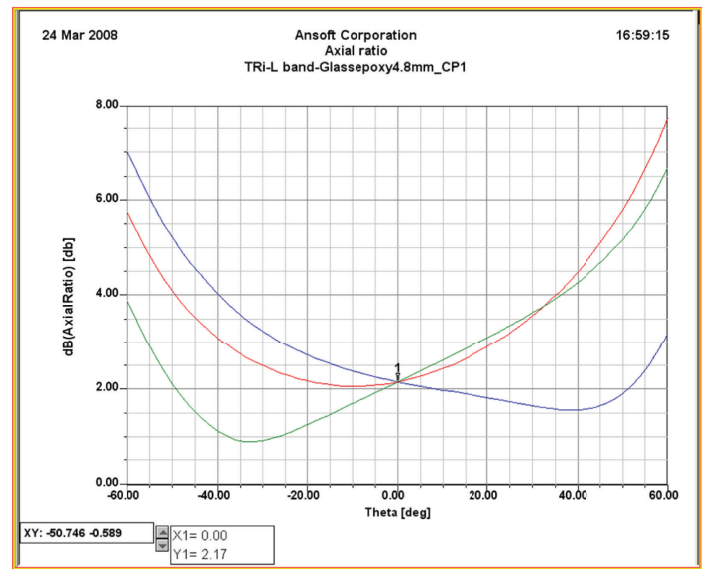

Figure 6: Axial ratio.

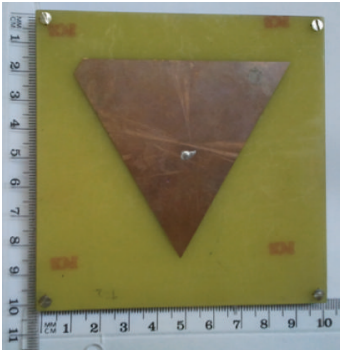

(a)

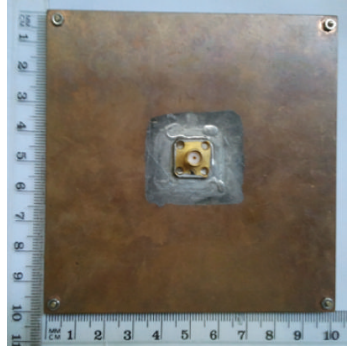

(b)
FIGURE 7: Developed 1.176 GHz antenna: left-radiation face, rightground face with $3 \mathrm{~mm}$ Via.

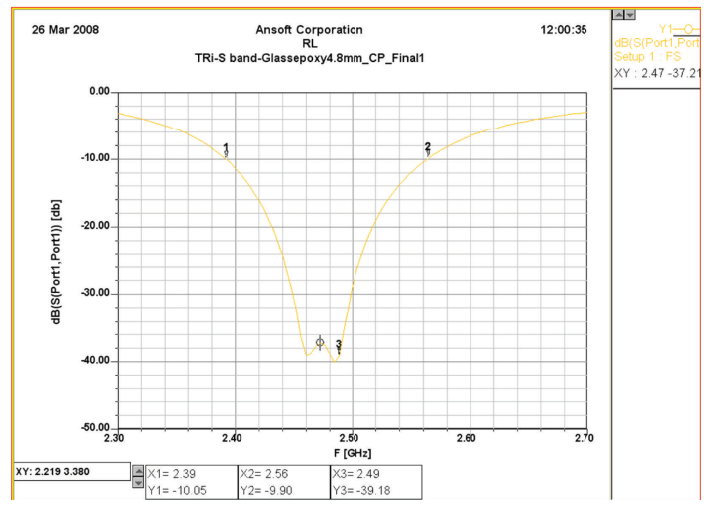

FIgURE 8: Simulated return loss.

for $2.487 \mathrm{GHz}$ antenna. Ansoft designer has been employed to simulate the required specifications of the antenna. The following subsection deals with the results in terms of return loss, bandwidth, smith plot, axial ratio, and gain radiation pattern for this antenna.

5.2.1. Outcomes. Simulated return loss diagram has been presented in Figure 8 using RF design tool, Ansoft designer version 2 software. It shows that the antenna is resonating at $2.487 \mathrm{GHz}$ frequency and providing the superior bandwidth of $170 \mathrm{MHz}$ ranging from $2.39 \mathrm{GHz}$ to $2.56 \mathrm{GHz}$ at the level of $10 \mathrm{~dB}$ return loss. This value of bandwidth is obtained after several iterations with optimized parameters in design. The measured return loss diagrams are shown in Figures 9 and 10 in presence of adhesive and the air gap, respectively. Again, there is same problem for stacking the sheets of glass epoxy due to unavailability of $4.48 \mathrm{~mm}$ single sheet. This problem has been sorted out by stacking three sheets of $1.16 \mathrm{~mm}$ together using adhesive and using air gap in between the sheets. In both instances, the measurements have been carried out.

5.2.2. Results Analysis. For $2.487 \mathrm{GHz}$ antenna, Figure 8 is showing that the antenna is resonating at $2.487 \mathrm{GHz}$ corresponding to data cursor 3 where as data cursor 1 and 2 at the level of $10 \mathrm{~dB}$ providing a good bandwidth of approximately $170 \mathrm{MHz}$ ranging from $2.39 \mathrm{GHz}$ to $2.56 \mathrm{GHz}$. The measured return loss with adhesive and air gap has 


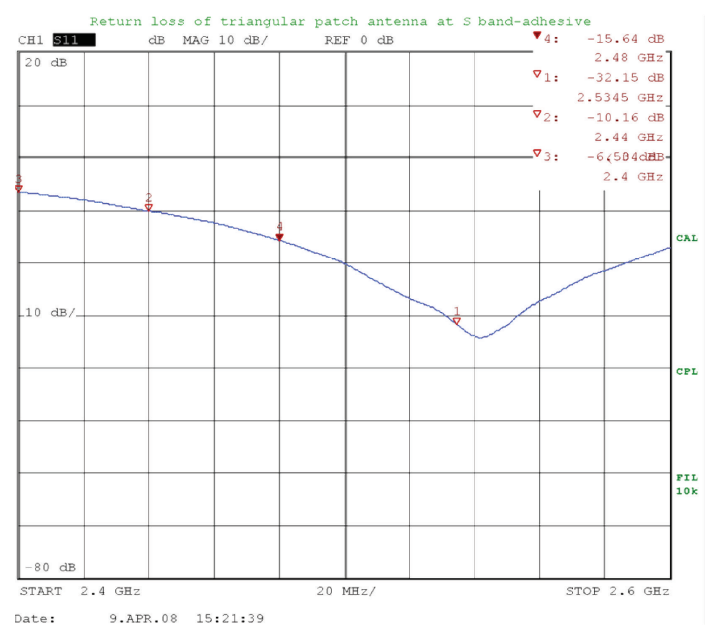

FIGURE 9: Measured retun loss using adhesive.

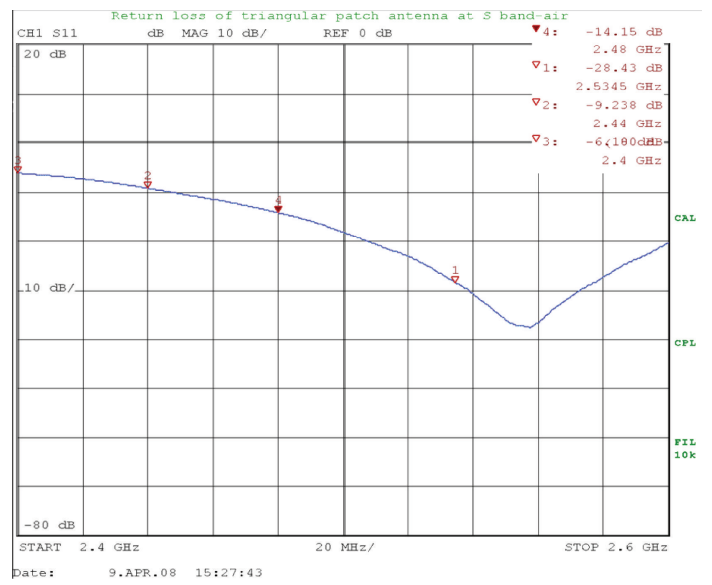

Figure 10: Measured retun loss using air gap.

been shown in Figures 9 and 10, respectively. In our design the center frequency is $2.487 \mathrm{GHz}$ but the measured center frequency using Vector Network Analyzer is $2.5345 \mathrm{GHz}$, which is shifted toward the right. The possible reasons for center frequency shift and bandwidth are the same as in the case of $1.176 \mathrm{GHz}$ antenna. Similarly the return loss of the antenna is measured with the air gap in between the sheets of the glass epoxy, which is also shifted due to the change in the effective dielectric material of the antenna.

The impedance plot for this antenna had shown that there was a loop formation near 1.0, which indicates that the antenna is circularly polarized, and inductive reactance is created by a change in thickness of actual hardware. The resonant frequency, that is, $2.487 \mathrm{GHz}$, is at the nearest point in the loop that shows the perfect behavior of the patch antenna. The measuring smith chart for both adhesive and air gap $2.487 \mathrm{GHz}$ antenna have been performed. Here also the measured and simulated smith plots are nearly similar.

From gain radiation pattern, shown in Figure 11, it can be stated that the gain along the bore sight is around $5.07 \mathrm{dBi}$. The radiation pattern has been manipulated for

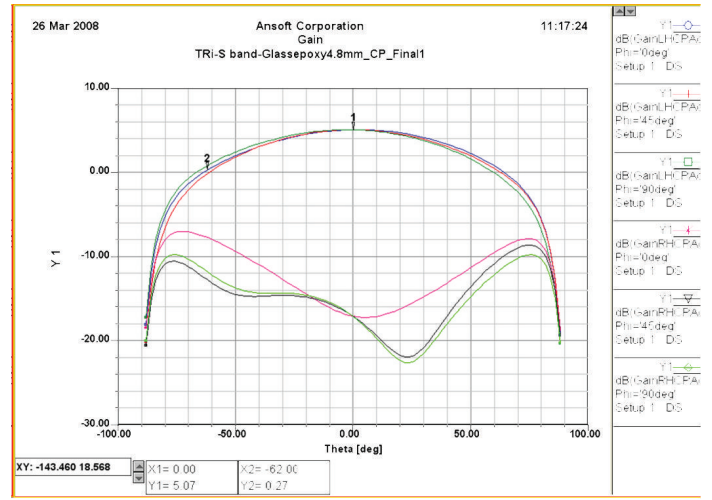

FIGURE 11: Gain radiation pattern.

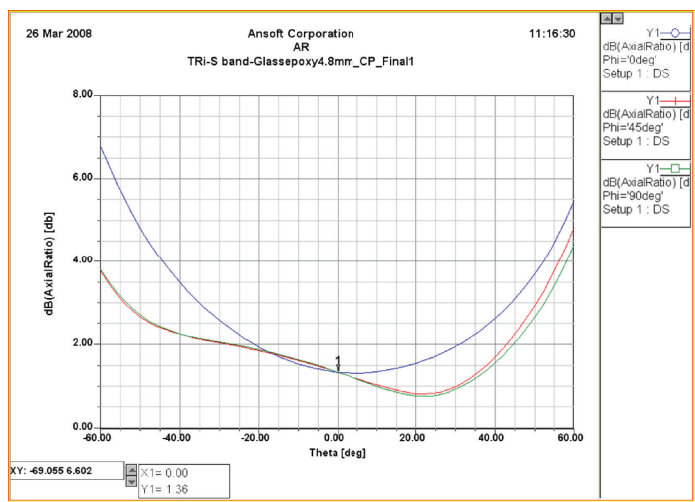

Figure 12: Axial Ratio.

three different angles of $\Phi$ that is, $0^{\circ}, 45^{\circ}$ and $90^{\circ}$, which gives the pattern appropriate to the specification. For the angle theta $(\theta)$ of $\pm 62^{\circ}$ the gain pattern is reasonable. The axial ratio for the specified patch antenna is shown in Figure 12. It has been shown that the axial ratio is $1.36 \mathrm{~dB}$ and in practical case it should be less than $3 \mathrm{~dB}$. Hence this also fulfills the requirement of the design. Figure 13 is the actual $2.487 \mathrm{GHz}$ antenna developed fulfilling the required specification showing its patch side where as the other side of the antenna has a coaxial probe, soldered with the patch through $3 \mathrm{~mm}$ Via.

\section{Fabrication Process}

The antenna artwork has been composed using a software tool, AutoCAD 2000. Here, the whole fabrication process flow is presented briefly. The photoetching process utilizes the final schematic constructed in AutoCAD 2000. Following steps have been carried to perform the etching process.

(i) Cutting and lamination as per antenna layout

(ii) Scanning and making film for desired pattern of the layout on the laminate.

(iii) Etching process where the scanned laminate use chemical liquid to wipe off the unwanted copper area. 


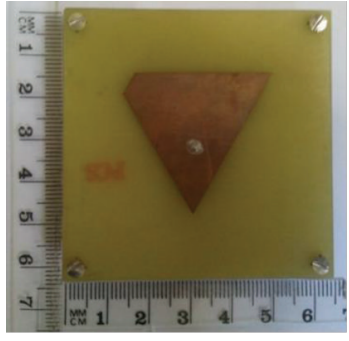

(a)

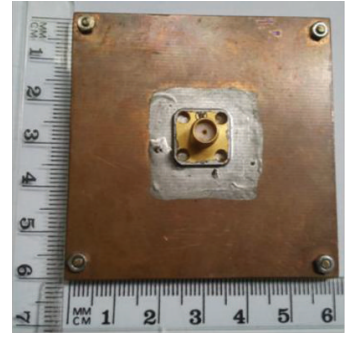

(b)
FIGURE 13: Developed 2.487 GHz antenna: left-radiation face, rightground face with $3 \mathrm{~mm}$ Via.

TABLE 2: Measurement of $1.176 \mathrm{GHz}$ antenna.

\begin{tabular}{lccc}
\hline $\begin{array}{l}\text { Serial } \\
\text { number }\end{array}$ & Parameters & Value & Unit \\
\hline$(1)$ & Measured center frequency & 1.21 & $\mathrm{GHz}$ \\
$(2)$ & Retun loss (adhesive) & Better than $10 \mathrm{~dB}$ & \\
$(3)$ & Return loss at 1.176 & 3.3 & $\mathrm{~dB}$ \\
\hline
\end{tabular}

The Fabrication process begins with the final drawing layout of $1.176 \mathrm{GHz}$ triangular patch, $2.487 \mathrm{GHz}$ triangular patch designed using simulation software tool. This layout is exported to the AutoCAD 2000 and saving it in DXF format, as this format of layout has easily been readable by film making machine. This machine changes the DXF format into the gbx (Gerber) format and the resolution of the machine was set to $10000 \mathrm{dpi}$. The machine is capable of producing the film up to $20000 \mathrm{dpi}$ and it utilizes the transparent photo plotter film of size 24 inch by 28 inch. The machine is capable of printing copper patch on the glass epoxy substrate using subtractive printing methodology. Presently, several additive printing technology and equipments are available in market.

Then the film was sent to fabrication where etching, rinsing, scrapping, and drying processes were carried out. The $50 \mathrm{ohm}$ SMA is the soldered at the feeding point of the fabricated antenna.

\section{Measurement}

After developing the antennas, their required performances have been measured. The return loss of the antennas has been measured with Vector Network Analyzer (VNA). The observed measurement values for the $1.176 \mathrm{GHz}$ antenna are shown in Table 2. In our design, the center frequency is $1.176 \mathrm{GHz}$ but the measured center frequency using Vector Network Analyzer is $1.226 \mathrm{GHz}$, which is shifted toward the right.

In the similar manner, $2.487 \mathrm{GHz}$ antenna has been developed and measured its required characteristics. Here again the return loss of the antenna has been measured with Vector Network Analyzer (VNA). Table 3 demonstrates the observed measurement values for the $2.487 \mathrm{GHZ}$ antenna. In the similar way, return loss of the antenna has been measured in presence of air gap in between the sheets of the glass epoxy.
TABLE 3: Measurement of $2.487 \mathrm{GHz}$ antenna.

\begin{tabular}{lccc}
\hline $\begin{array}{l}\text { Serial } \\
\text { number }\end{array}$ & Parameters & Value & Unit \\
\hline$(1)$ & Measured center frequency & 2.53 & $\mathrm{GHz}$ \\
$(2)$ & Retun loss (adhesive) & Better than $10 \mathrm{~dB}$ & \\
$(3)$ & Return loss at 2.487 & 3.1 & $\mathrm{~dB}$ \\
\hline
\end{tabular}

\section{Conclusion and Future Works}

Our research makes significant contributions in the field of electromagnetic modeling and antenna design. Obvious practical implications of our results reveals that successive and iterative optimization on the parameters of microstrip antenna leads to achieve the required performances suitable for specific applications. We performed the modelings based on glass epoxy as a substrate material and copper as a radiating patch. The measured performances such as return loss, frequency of operation, bandwidth, and axial ratio have the similar characteristics as of obtained theoretically using simulating tool. We have found slight shift in the frequencies due to stacking of the glass epoxy sheets. The gain radiation pattern has been measured and found better than expected. This research has made possible to fabricate an antenna satisfying the required specifications and allowing us to create a compact and low-cost tip-truncated triangular antenna.

There are several avenues for further research. The first important future work is to reflect on optimization of technology. In our earlier studies [19-24], we have analyzed additive printing methodologies for RFID-based applications and investigated environmental friendly designs for printed antenna. Therefore, first important future work is to analyze several printing methodology for such antenna technology and evaluate their environmental impacts and resources utilized in both technologies. Another imperative future work is to improve the efficiency of the designed antenna using latest numerical techniques and recent electromagnetic modeling tool. Finally, it would be worthwhile to examine the role of copper traced printed antennas and to explore its environmental emissions during manufacturing process.

\section{Acknowledgment}

The authors would like to thank iPack Centre, Royal Institute of Technology, KTH, for providing software tools and necessary supports to carry out these investigations.

\section{References}

[1] A. O. Karilainen, P. M. T. Ikonen, C. R. Simovski et al., "Experimental studies on antenna miniaturisation using magnetodielectric and dielectric materials," IET Microwaves, Antennas \& Propagation, vol. 5, no. 4, pp. 495-502, 2011.

[2] S. Fargeot, A. Julien-Vergonjanne, and P. Guillon, "Dielectric resonator antenna for material characterization," in Proceedings of the International Conference on Precision Electromagnetic Measurements Digest, pp. 70-71, June 1996. 
[3] A. Louzir, P. Minard, and J. F. Pintos, "Parametric study on the use of magneto-dielectric materials for antenna miniaturization," in Proceedings of the IEEE International Symposium (APSURSI) on Antennas and Propagation Society, pp. 1-4, July 2010.

[4] K. D. Jang, J. H. Kim, D. H. Lee, G. H. Kim, W. M. Seong, and W. S. Park, "A small CRLH-TL metamaterial antenna with a magneto-dielectric material," in Proceedings of the International Symposium ob Antennas and Propagation Society (AP-S '08), pp. 1-4, July 2008.

[5] G. Kumar and K. P. Ray, "Chapter-2: regularly shaped broadband MSAs," in A Book on Broadband Microstrip Antenna, Artech House Antennas and Propagation Library, pp. 32-81, 2002.

[6] R. K. Kanth, A. K. Singhal, P. Liljeberg, and H. Tenhunen, "Design of multiband fractal antenna for mobile and handheld terminals," in Proceedings of the 1st Asian Himalayas International Conference on Internet (AH-ICI '09), pp. 1-4, November 2009.

[7] R. K. Kanth, W. Ahmad, Y. Amin, P. Liljeberg, L.-R. Zheng, and $\mathrm{H}$. Tenhunen, "Analysis, design and development of novel, low profile microstrip antenna for satellite navigation," in Proceedings of the 14th International Symposium on Antenna Technology and Applied Electromagnetics of the American Electromagnetics Conference (ANTEM-AMEREM '10), pp. 14, July 2010.

[8] R. K. Kanth, W. Ahmad, Y. Amin, P. Liljeberg, L. R. Zheng, and H. Tenhunen, "Analysis, design and development of novel, low profile $2.487 \mathrm{GHz}$ microstrip antenna," in Proceedings of the 14th International Symposium on Antenna Technology and Applied Electromagnetics and the American Electromagnetics Conference (ANTEM/AMEREM '10), July 2010.

[9] R. K. Kanth, W. Ahmad, S. Shakya, P. Liljeberg, L.-R. Zheng, and H. Tenhunen, "Autonomous use of fractal structure in low cost, multiband and compact navigational antenna," in Proceedings of the 10th Mediterranean Microwave Symposium (MMS '10), pp. 135-138, August 2010.

[10] H. Kumar, R. Kumar Kanth, P. Liljeberg, and H. Tenhunen, "Metamaterial based slotted patch antenna," in Proceedings of the 10th International Conference on Telecommunication in Modern Satellite Cable and Broadcasting Services (TELSIKS '11), vol. 1, pp. 43-46, 2011.

[11] H. Kumar, M. D. Upadhayay, R. K. Kanth, and P. Lijeberg, "Study of electronically tunable circular patch antenna," in Proceedings of the 10th International Conference on Telecommunication in Modern Satellite Cable and Broadcasting Services (TELSIKS '11), vol. 2, pp. 536-539, 2011.

[12] A. Thabet, A. Z. El Dein, and A. Hassan, "Design of compact microstrip antenna by using new nanocomposite materials," in Proceedings of the IEEE 4th International Conference on Nanoelectronics (INEC'11), pp. 1-2, 2011.

[13] Y. Ushijima, E. Nishiyama, and M. Aikawa, "Dualpolarized microstrip array antenna with orthogonal feed circuit," in Proceedings of the IEEE International Symposium on Antennas and Propagation (APSURSI'11), pp. 561-564, 2011.

[14] J. H. Kim, C. K. Hyeon, and K. Chun, "Performance enhancements of a microstrip antenna with multiple layer substrates," in Proceedings of the International Symposium on Signals, Systems and Electronics (ISSSE '07), pp. 319-322, August 2007.

[15] T. Seki, N. Honma, K. Nishikawa, and K. Tsunekawa, "Millimeter-wave high-efficiency multilayer parasitic microstrip antenna array on teflon substrate," IEEE Transactions on Microwave Theory and Techniques, vol. 53, no. 6, pp. 21012106, 2005.
[16] T. J. Ellis, J.-P. Raskin, G. M. Rebeiz, and L. P. Katehi, "A wide-band CPW-fed microstrip antenna at millimeter-wave frequencies," in Proceedings of the International Symposium on Antennas and Propagation Society IEEE, vol. 2, pp. 1220-1223, 1999.

[17] C. Y. Huang and C. W. Ling, "CPW feed circularly polarised microstrip antenna using asymmetric coupling slot," Electronics Letters, vol. 39, no. 23, pp. 1627-1628, 2003.

[18] K. Kumar and N. Gunasekaran, "A novel wideband slotted $\mathrm{mm}$ wave microstrip patch antenna," in Proceedings of the International Conference on Signal Processing, Communication, Computing and Networking Technologies (ICSCCN '11), pp. 10-14, 2011.

[19] R. K. Kanth, Q. Wan, H. Kumar, P. Liljeberg, L. Zheng, and H. Tenhunen, "Life cycle assessment of printed antenna: comparative analysis and environmental impacts evaluation," in Proceedings of the IEEE International Symposium on Sustainable Systems and Technology (ISSST '11), May 2011.

[20] R. K. Kanth, Q. Wan, P. Liljeberg, L. Zheng, and H. Tenhunen, "Insight into quantitative environmental emission analysis of printed circuit board," in Proceedings of the 10th International Conference on Environment and Electrical Engineering (EEEIC.EU'11), pp. 1-4, May 2011.

[21] R. K. Kanth, P. Liljeberg, H. Tenhunen et al., "Evaluating sustainability, environmental assessment and toxic emissions during manufacturing process of RFID based systems," in Proceedings of the IEEE 9th International Conference on Dependable, Autonomic and Secure Computing (DASC'11), pp. 1066-1071, 2011.

[22] R. K. Kanth, P. Liljeberg, H. Tenhunen et al., "Comparative end-of-life study of polymer and paper based radio frequency devices," International Journal of Environmental Protection, vol. 2, no. 8, pp. 23-27, 2012.

[23] R. K. Kanth, Q. Wan, H. Kumar et al., "Evaluating sustainability, environment assessment and toxic emissions in life cycle stages of printed antenna," Procedia Engineering, vol. 30, pp. 508-513, 2012.

[24] R. K. Kanth, Q. Wan, P. Liljeberg, A. Tuominen, L. Zheng, and $\mathrm{H}$. Tenhunen, "Investigation and evaluation of life cycle assessment of printed electronics and its environmental impacts analysis," in Proceedings of the NEXT Conference (NEXT '10), pp. 52-67, October 2010. 

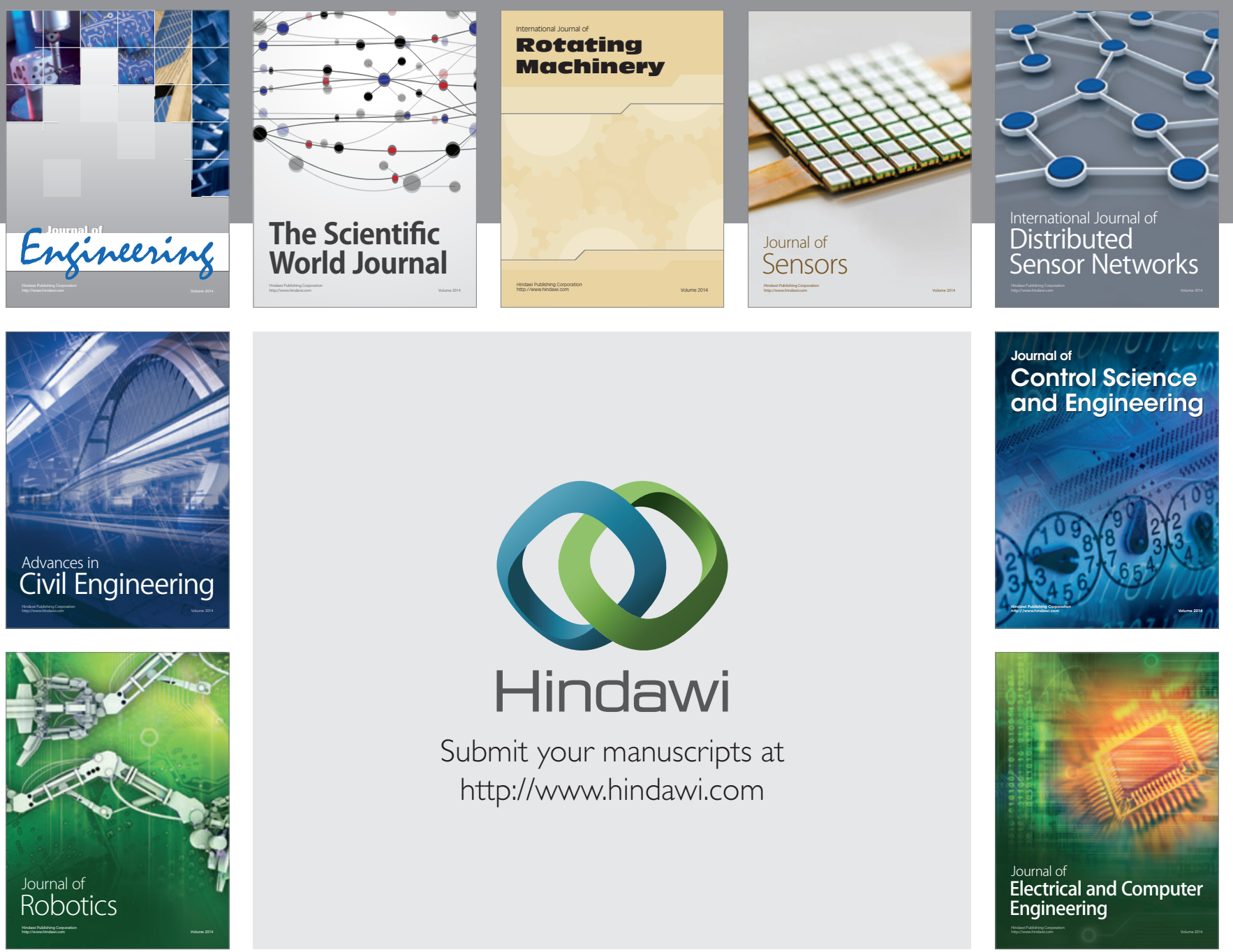

Submit your manuscripts at

http://www.hindawi.com
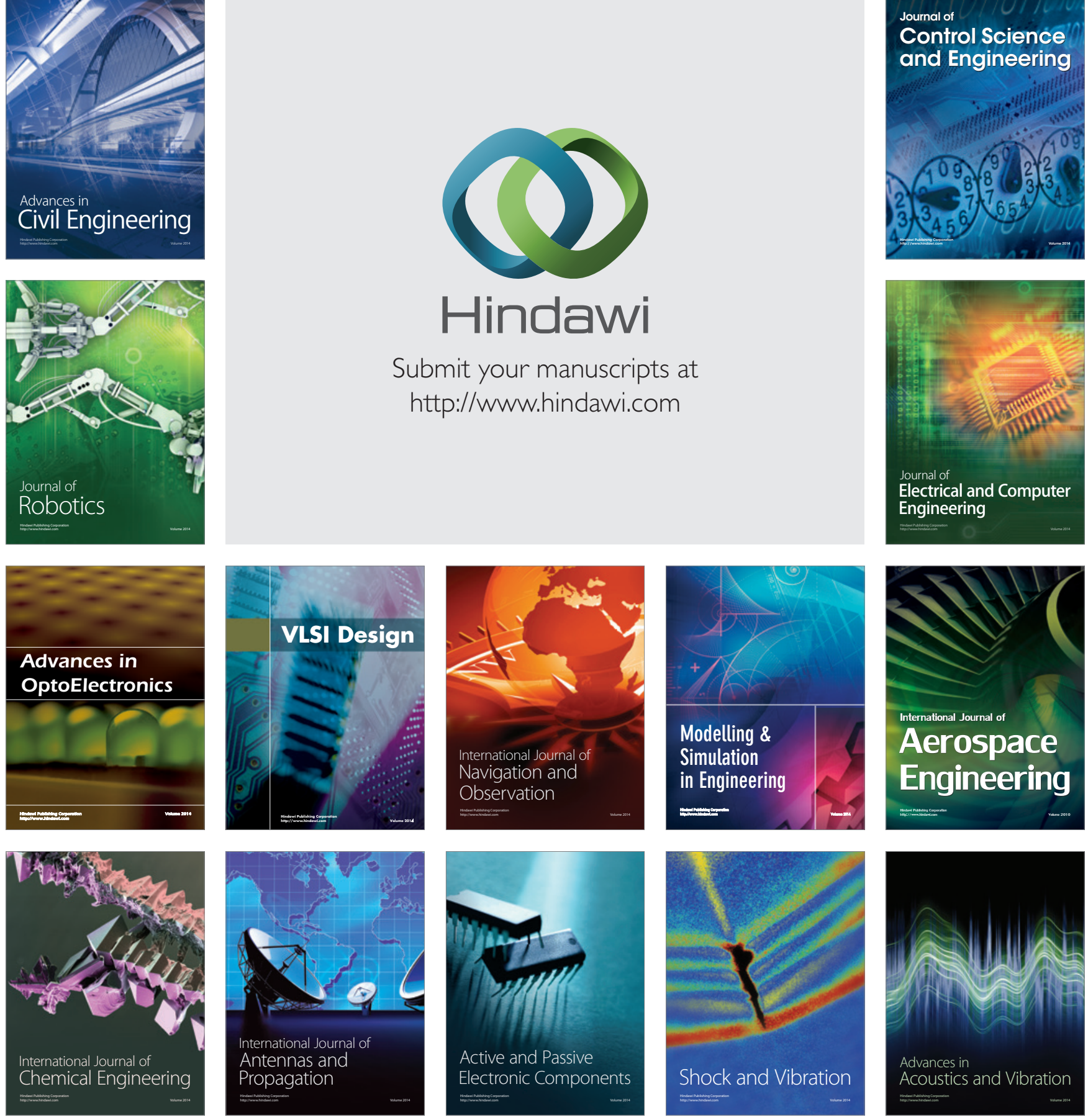